\title{
Lipossomas e suas aplicações terapêuticas: Estado da arte
}

\author{
Cinthia Meireles Batista ${ }^{1,2}$, Cícero Moraes Barros de Carvalho², Nereide Stela Santos \\ Magalhães ${ }^{2,3 *}$
}

\begin{abstract}
${ }^{1}$ Departamento de Farmácia, Universidade Federal de Pernambuco, ${ }^{2}$ Laboratório de Imunopatologia Keizo-Asami (LIKA), Universidade Federal de Pernambuco, ${ }^{3}$ Departamento de Bioquímica, Universidade Federal de Pernambuco
\end{abstract}

*Correspondência:

N. S. S. Magalhães

Universidade Federal de Pernambuco (UFPE)

Grupo de Sistemas de Liberação

Controlada de Medicamentos

Laboratório de Imunopatologia KeizoAsami (LIKA)

Av. Prof. Moraes Rego, 1235, Cidade Universitária

50670-901 - Recife - PE, Brasil

E-mail: nssm@ufpe.br
Lipossomas são vesículas constituídas de uma ou mais bicamadas fosfolipídicas orientadas concentricamente em torno de um compartimento aquoso e servem como carreadores de fármacos, biomoléculas ou agentes de diagnóstico. A estabilidade dos lipossomas pode ser afetada por fatores quimicos, físicos e biológicos. Após administração intravenosa, lipossomas convencionais são rapidamente capturados pelo sistema fagocitário mononuclear. Para evitar essa captura, lipossomas furtivos foram desenvolvidos, os quais apresentam a superficie modificada com componentes hidrofilicos. Para permitir a liberação seletiva do fármaco nos sítios alvos, ligantes de reconhecimento específico são conjugados na superfície de lipossomas. Em geral, os métodos de preparação de lipossomas incluem hidratação de um filme lipídico seguida de sonicação ou extrusão para redução do tamanho das vesículas. Os lipossomas são caracterizados quanto ao tamanho e composição química das vesículas e conteúdo do material encapsulado. Nesta revisão, constata-se que os lipossomas oferecem maior eficácia e segurança com relação aos tratamentos convencionais. Apesar de algumas formulações lipossomais serem comercializadas desde os anos 1980 para tratamento de infecções fúngicas sistêmicas e do câncer, problemas de ordem tecnológica e biológica fazem com que os lipossomas sejam ainda extensivamente estudados para desenvolvimento de formulações estáveis no organismo visando à terapia de várias doenças, principalmente do câncer.

\author{
Unitermos \\ - Lipossomas/Aplicações \\ terapêuticas \\ - Fosfolipídios \\ - Lipossomas/Estabilidade
}

\section{INTRODUÇÃO}

Alec Bangham há 40 anos com sua observação pioneira de que fosfolipídeos em soluções aquosas podem formar estruturas fechadas em bicamadas, permitiu que a pesquisa sobre os lipossomas percorresse um longo caminho, convertendo-os de simples objetos de pesquisa biofísica em carreadores terapêuticos para numerosas aplicações clínicas (Torchilin, 2005).

Os primeiros resultados das pesquisas foram, entre- 
tanto, um tanto desapontadores principalmente devido à instabilidade físico-química e biológica dos lipossomas e pela baixa eficiência na encapsulação de fármacos. A utilidade dos lipossomas foi melhorada seguindo pesquisas básicas que permitiram o aumento da estabilidade e a compreensão das características físico-químicas e interação com fluidos biológicos. O pré-requisito para o uso de lipossomas como carreadores de fármacos é a utilização de métodos que permitam a caracterização e controle de fatores como preparação, tamanho das vesículas, composição, estabilidade e taxa de encapsulação de fármacos, visto que estes fatores influenciam diretamente no comportamento dos lipossomas em meio biológico (Lasic, 1998).

O aumento da eficiência de encapsulação e de liberação do fármaco in vivo constitui o principal alvo das pesquisas envolvendo lipossomas. No presente trabalho de revisão, o objetivo consiste em apresentar os métodos de fabricação, as características e as principais aplicações terapêuticas destes carreadores.

\section{LIPOSSOMAS}

Lipossomas são vesículas microscópicas compostas de uma ou mais bicamadas lipídicas concêntricas, separadas por um meio aquoso. Eles podem encapsular substâncias hidrofílicas e/ou lipofílicas, sendo que as primeiras ficam no compartimento aquoso e as lipofílicas inseridas ou adsorvidas na membrana. Por serem biodegradáveis, biocompatíveis e não imunogênicos são altamente versáteis para pesquisa, terapêutica e aplicações analíticas (Edwards,
Baeumner, 2006; New, 1990; Puisieux et al., 1995).

Estas vesículas são constituídas basicamente por fosfolipídeos (podendo ser de natureza sintética ou natural), esteróis e um antioxidante (Vemuri, Rhodes, 1995). Os lipídeos mais utilizados nas formulações de lipossomas são os que apresentam uma forma cilíndrica como as fosfatidilcolinas, fosfatidilserina, fosfatidilglicerol e esfingomielina, que tendem a formar uma bicamada estável em solução aquosa. As fosfatidilcolinas são as mais empregadas em estudos de formulação de lipossomas, pois apresentam grande estabilidade frente a variações de $\mathrm{pH}$ ou da concentração de sal no meio.

Os fosfolipídeos são caracterizados por uma temperatura de transição de fase ( $\mathrm{Tc}$ ), na qual a membrana passa de uma fase gel, onde a cadeia hidrocarbonada do lipídeo está em estado ordenado, para uma fase de cristal-líquido, onde as moléculas ficam com movimentos mais livres e os radicais hidrofílicos agrupados tornam-se completamente hidratados. O comprimento e a saturação da cadeia lipídica influenciam o valor da Tc. Portanto, diferentes membranas compostas por lipídeos distintos podem exibir diferentes níveis de fluidez na mesma temperatura (Frézard, 2005; Lasic, 1998). A permeabilidade dos lipossomas é relativamente baixa quando a temperatura é menor que a Tc dos lipossomas, sendo a mesma medida pelo fluxo ou pela taxa em que o soluto sai do compartimento aquoso, através da bicamada. Esta propriedade vai depender, no entanto, da natureza do soluto e da fluidez da membrana (Tabela I) (Frézard, 1999).

Os lipossomas podem conter uma única bicamada lipídica ou bicamadas múltiplas em torno do compartimen-

TABELA I - Exemplos de fosfolipídios utilizados na preparação de lipossomas e suas respectivas temperaturas de transição de fase (Tc) e a carga da molécula

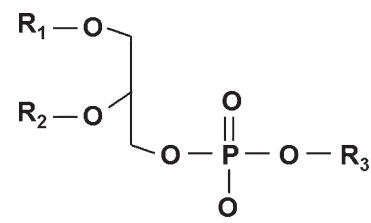

\begin{tabular}{lllll}
\hline Fosfolipídios $\left(\mathrm{R}_{3}\right)$ & Cadeia hidrofóbica de ácido graxo $\left(\mathrm{R}_{1}, \mathrm{R}_{2}\right)$ & Nomenclatura e abreviatura & Tc $\left({ }^{\circ} \mathrm{C}\right)$ & Carga \\
\hline Fosfatidilcolina $(\mathrm{PC})$ & $\mathrm{CH}_{3}-\left(\mathrm{CH}_{2}\right)_{7}-\mathrm{CH}=\mathrm{CH}-\left(\mathrm{CH}_{2}\right)_{7}-(\mathrm{O})-$ & Dioleilfosfatidilcolina (DOPC) & $<0$ & Anfótera \\
$\mathrm{CH}_{2} \mathrm{CH}_{2} \mathrm{~N}+\left(\mathrm{CH}_{3}\right)_{3}$ & $\mathrm{CH}_{3}-\left(\mathrm{CH}_{2}\right)_{12}-\mathrm{C}(\mathrm{O})-$ & Dimiristoilfosfatidilcolina (DMPC) & 23 & Anfótera \\
& $\mathrm{CH}_{3}-\left(\mathrm{CH}_{2}\right)_{14}-\mathrm{C}(\mathrm{O})-$ & Dipalmitoilfosfatidilcolina (DPPC) & 42 & Anfótera \\
& $\mathrm{CH}_{3}-\left(\mathrm{CH}_{2}\right)_{16}-\mathrm{C}(\mathrm{O})-$ & Diestearoilfosfatidilcolina (DSPC) & 55 & Anfótera \\
\hline Fosfatidiletanolamina (PE) & $\mathrm{CH}_{3}-\left(\mathrm{CH}_{2}\right)_{7}-\mathrm{CH}=\mathrm{CH}-\left(\mathrm{CH}_{2}\right)_{7}-(\mathrm{O})-$ & Dioleilfosfatidiletanolamina (DOPE) & $<0$ & Anfótera \\
$\mathrm{CH}_{2} \mathrm{CH}_{2} \mathrm{NH}_{3}^{+}$ & $\mathrm{CH}_{3}-\left(\mathrm{CH}_{2}\right)_{16}-\mathrm{C}(\mathrm{O})-$ & Diestearoilfosfatidiletanolamina (DSPE) & 74 & Anfótera \\
\hline Fosfatidilglicerol $(\mathrm{PG})$ & $\mathrm{CH}_{3}-\left(\mathrm{CH}_{2}\right)_{12}-\mathrm{C}(\mathrm{O})-$ & Dimiristoilfosfatidilglicerol (DMPG) & 13 & Negativa \\
$\mathrm{CH}_{2} \mathrm{CHOHCH}_{2} \mathrm{OH}$ & $\mathrm{CH}_{3}-\left(\mathrm{CH}_{2}\right)_{14}-\mathrm{C}(\mathrm{O})-$ & Dipalmitoilfosfatidilglicerol (DPPG) & 35 & Negativa \\
\hline Fosfatidilserina $(\mathrm{PS})$ & $\mathrm{CH}_{3}-\left(\mathrm{CH}_{2}\right)_{14}-\mathrm{C}(\mathrm{O})-$ & Dipalmitoilfosfatidilserina (DPPS) & 79 & Negativa \\
$\mathrm{CH}_{2} \mathrm{CHNH}_{3}{ }^{+} \mathrm{COO}-$ & $\mathrm{CH}_{3}-\left(\mathrm{CH}_{2}\right)_{16}-\mathrm{C}(\mathrm{O})-$ & Diestearoilfosfatidilserina (DSPS) & 79 & Negativa \\
\hline
\end{tabular}


to aquoso interno e, portanto, são classificados em unilamelar e multilamelar, respectivamente. Quanto ao tamanho, as vesículas unilamelares podem ser pequenas ou grandes, sendo caracterizadas como lipossomas unilamelares pequenos - SUV (small unilamellar vesicles) e lipossomas unilamelares grandes - LUV (large unilamellar vesicles). Com relação ao método de preparação, os lipossomas podem ser caracterizados como: REV (vesículas obtidas por evaporação em fase reversa), FPV (vesículas obtidas em prensa de French) e EIV (vesículas obtidas por injeção de éter) (Lasic, 1998; Vemuri, Rhodes, 1995).

Na evolução de seu emprego como carreadores de fármacos, algumas alterações foram realizadas na estrutura básica dos lipossomas possibilitando maior aplicação terapêutica (Figura 1), sendo também classificados quanto às características de interação com sistemas biológicos (Torchilin, 2005).

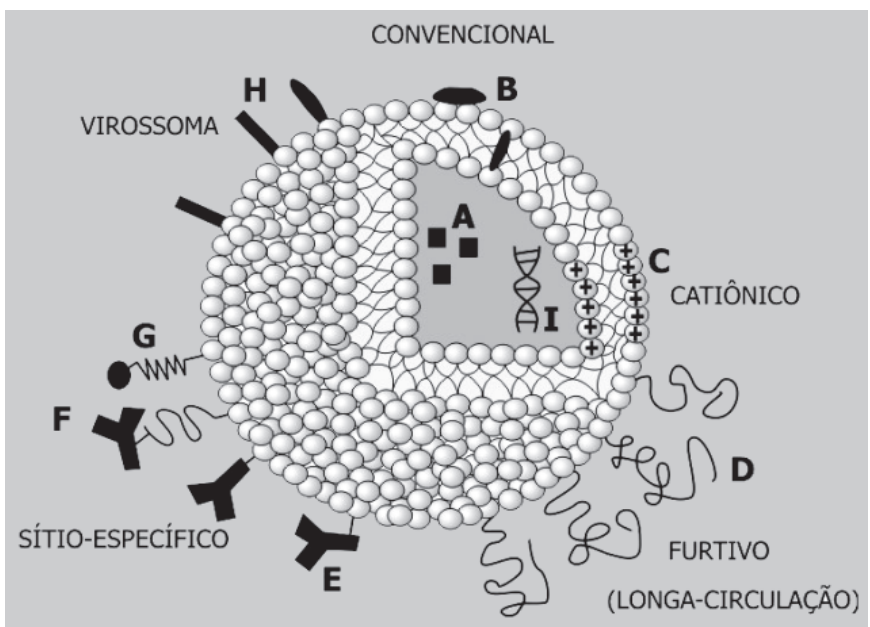

FIGURA 1 - Características estruturais dos vários tipos de lipossomas: convencionais - (A) fármaco hidrofílico no interior do lipossoma e (B) fármaco lipofílico adsorvido ou inserido na bicamada lipídica; catiônico (C); de longa circulação $\left(\right.$ Stealth $\left.^{\circledR}\right)$ - com polímero hidrofílico na superfície (D); sítio-específicos - (E), (F) com anticorpos ligantes e (G) com peptídeos e proteínas ligantes na superfície; virossomas - com envelope viral na superfície (H); (I) DNA-plasmídeo encapsulado em lipossomas catiônicos.

\section{Lipossomas convencionais}

Lipossomas convencionais são compostos de fosfolipídeos e colesterol, além de um lipídeo com carga negativa ou positiva para evitar a agregação das vesículas, aumentando a estabilidade em suspensão. In vivo os lipossomas convencionais são reconhecidos pelo sistema fagocitário mononuclear, sendo, então, rapidamente removidos da circulação (Vemuri, Rhodes, 1995).

\section{Lipossomas de longa circulação}

Lipossomas de longa duração in vivo são obtidos por diferentes métodos, incluindo o revestimento da superfície lipossômica com componentes hidrofílicos naturais como o monossialogangliosideo GM1 e fosfatidilinositol, ou de polímeros hidrofílicos sintéticos, especificamente os polietilenoglicóis (PEG) (Sagristá et al., 2000; Torchilin, 2005). A camada hidrofílica superficial destes polímeros aumenta o tempo de circulação dos lipossomas prevenindo o reconhecimento e conseqüente associação com as opsoninas no plasma, desse modo, inibindo o processo de reconhecimento molecular e a captura pelas células do sistema fagocitário mononuclear, principalmente as células de Kupffer no fígado (Needham et al., 1992).

\section{Lipossomas sítio-específicos}

Na tentativa de aumentar a especificidade de interação de lipossomas com células alvo e elevar a quantidade do fármaco liberado nestas células, a pesquisa neste campo foi focada no desenvolvimento de lipossomas direcionados ou sítio-específicos. Estes últimos utilizam ligantes acoplados em sua superfície, que conferem seletividade para distribuir o fármaco encapsulado no sítio de ação desejado (Sihorkar, Vyas, 2001; Sapra, Allen, 2003).

A superfície dos lipossomas pode ser modificada através da escolha de lipídeos que permitam a conjugação de uma variedade de elementos de reconhecimento. Derivados lipídicos reativos incluem aqueles com um grupo amino, como a fosfatidiletanolamina (PE), e um grupo hidroxila, usando colesterol ou polietilenoglicol. Os métodos para conjugação de ligantes de reconhecimento são baseados em agentes reticulantes heterobifuncionais, tais como o carboxilato de succinimidil-4-( $N$-maleididometila) (SMCC), butirato de $p$-maleimidofenila (MPB), ou interações não-covalentes como aquelas da biotinaestreptavidina. Alguns exemplos de ligantes de reconhecimento são os anticorpos, glicopeptídeos, polissacarídeos, proteínas virais e lectinas (Edwards, Baeumner, 2006).

- Imunolipossomas - Lipossomas contendo ligantes capazes de aumentar o acúmulo de fármacos encapsulados nas células e tecidos alvo. Imunoglobulinas (Ig) da classe (IgG) e seus fragmentos são os ligantes mais empregados (Torchilin, 2005);

- Lipossomas como carreadores de proteínas e peptídeos - Contêm na superfície compostos biologicamente ativos de origem protéica ou peptídica, como 
enzimas, hormônios peptídicos e citocinas. Estes lipossomas vêm sendo utilizados no tratamento de doenças hereditárias e do câncer (Torchilin, 2000);

- Virossomas - Os virossomas contêm hemaglutinina na superfície, a qual age como direcionador ligando-se a resíduos de ácido sialíco na membrana das células. Após endocitose dos virossomas o meio ácido dos endossomas promove modificação conformacional na hemaglutinina e em conseqüência os virossomas tornam-se fusogênicos e fusionam com a membrana endocítica. Os virossomas são utilizados para potencializar o efeito de vacinas encapsuladas com liberação específica do antígeno (Kaneda, 2000; Kersten, Crommelin, 2003).

\section{Lipossomas polimórficos}

Lipossomas polimórficos são aqueles que se tornam reativos devido à mudança na sua estrutura desencadeada por uma alteração de $\mathrm{pH}$, temperatura ou carga eletrostática.

- Lipossomas sensíveis ao pH - Estes carreadores são preparados com constituintes sensíveis ao $\mathrm{pH}$ como as fosfatidiletanolaminas insaturadas e hemissuccinato de colesterila. Esses lipossomas são utilizados para liberar o fármaco no citoplasma ou no tecido intersticial de células tumorais, visto que o $\mathrm{pH}$ desse meio é reduzido, comparado com o $\mathrm{pH}$ fisiológico normal (Derycke, Witte, 2004; Carvalho Jr. et al., 2007);

- Lipossomas termo-sensiveis - São formados por mistura de lipídeos sintéticos, como a dipalmitoilfosfatidilcolina (DPPC) e diestearoilfosfatidilcolina (DSPC), que possuem uma Tc alguns graus acima da temperatura fisiológica, temperatura essa facilmente alcançada em local de hipertermia como o tecido tumoral (Sandip et al., 2000);

- Lipossomas cationicos - Como o nome sugere, estes lipossomas apresentam carga positiva na superfície. Há duas décadas, com a descoberta de lipídeos catiônicos, estes lipossomas têm sido utilizados para liberação de ácidos nucléicos dentro das células (Dass, Choong, 2006). Os lipídeos catiônicos são moléculas anfifílicas compostas de uma ou duas cadeias de ácido graxo acopladas a um grupo éster e um grupamento aminíco hidrofílico (El-Aneed, 2004). A Figura 2 apresenta a estrutura do lipídeo catiônico 1,2-dioleoil-3-trimetilamônio-propano (DOTAP).

\section{Métodos de preparação de lipossomas}

Vários métodos são preconizados para a preparação dos diferentes tipos de lipossomas. A maioria dos métodos

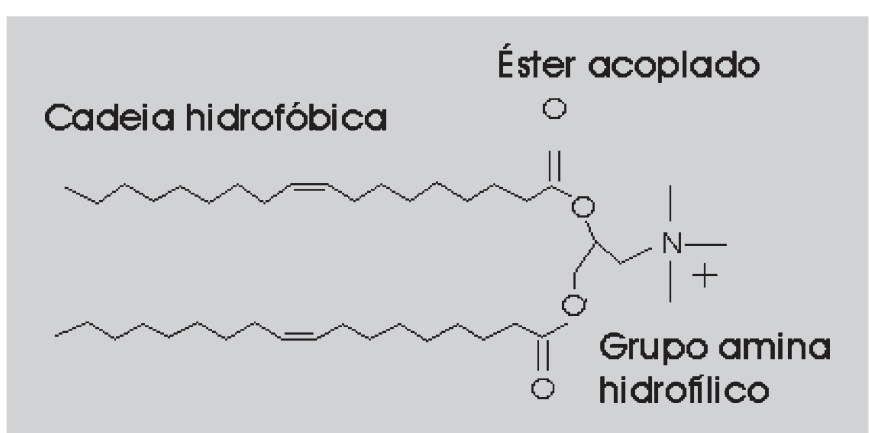

FIGURA 2 - Estrutura do lipídeo catiônico 1,2-dioleoil-3trimetilamônio-propano (DOTAP). A maioria dos outros lipídeos catiônicos tem estrutura geral semelhante.

inclui a hidratação de um filme lipídico, onde primeiramente os lipídeos são dissolvidos em solvente orgânico, seguido da evaporação do solvente com conseqüente formação do filme lipídico. A hidratação deste último pode ser efetuada com água ou solução tampão, sob agitação magnética vigorosa, promovendo a formação da dispersão de lipossomas multilamelares. O fármaco a ser encapsulado pode ser incorporado na solução tampão (hidrofílicos) ou dissolvido na mistura lipídica (lipofílicos). No entanto, a maior desvantagem deste método é a baixa encapsulação para fármacos hidrofílicos (Sharma, Sharma, 1997).

A partir da dispersão de MLV's, diferentes métodos são utilizados para produzir dispersões homogêneas de SUV's e LUV's, podendo-se empregar processos mecânicos, eletrostáticos ou químicos. Os mais freqüentes são os processos mecânicos, em que estão incluídos: extrusão através de membranas de policarbonato com diferentes porosidades, prensa de French ou uso de homogeneizador/ microfluidificador e a sonicação (Lasic, 1993). SUV's e LUV's também podem ser preparados pelo método de injeção de etanol ou éter (processo químico). Neste método, os lipídeos são dissolvidos no solvente e então injetados em solução aquosa aquecida, seguido de evaporação do solvente (Lasic, 1993).

\section{Escalonamento da produção de Lipossomas}

Diferentes métodos de preparação de lipossomas em escala laboratorial são propostos para obtenção de 1 a $10 \mathrm{~mL}$ de preparação, tais como redispersão de um filme lipídico, para produção de MLV, seguido de sonicação, extrusão e microfluidificação para obtenção de SUV ou LUV (New, 1990; Puisieux et al., 1995). Entretanto, os dois últimos métodos podem ser também utilizados em escala industrial. A microfluidificação é fundamentada nos princípios da dinâmica de fluidos para produção de lipossomas em processo contínuo, o qual é compatível com as boas práticas de fabricação de produtos farmacêuticos. 
A produção industrial de lipossomas teve início somente em meados dos anos 1980, devido à solução tardia de problemas tecnológicos e de controle de qualidade dos processos de produção em larga escala. Dentre esses, o fornecimento de matéria-prima (lipídios e fosfolipídios) de alta qualidade, reprodutibilidade do processo de produção em larga escala, validação dos ensaios de controle de qualidade de processos e do produto acabado, estabilidade físicoquímica em longo prazo das preparações lipossômicas e obtenção de produtos lipossômicos estéreis (Wagner et al., 2002). A esterilização de lipossomas constitui um grande problema na produção industrial de lipossomas, visto que o único método plausível seria a esterlização por filtração, a qual não elimina os pirogênios. No entanto, Kikuchi e colaboradores (1991) propuseram que o método de esterilização convencional pelo calor $\left(120^{\circ} \mathrm{C}, 20 \mathrm{~min}\right)$ não afeta a estabilidade química ou a taxa de encapsulação de lipossomas contendo fármacos.

Recentemente, outros métodos foram propostos para preparação de lipossomas em escala piloto com possibilidade de escalonamento para a escala industrial, como o método de injeção de etanol com fluxo cruzado, utilizando um módulo de injeção múltipla (Wagner et al., 2002) baseado na técnica de injeção de etanol (New, 1990; Puisieux et al., 1995). A preparação de lipossomas através da técnica de injeção com fluxo cruzado ocorre em ambiente estéril, sem o imperativo de esterilização posterior do produto acabado, sendo o equipamento qualificado para despirogenização e adaptado para esterilização pelo calor.

Mais recentemente, o método de aquecimento de uma dispersão de fosfolipídios e colesterol em glicerol a $120^{\circ} \mathrm{C}$ permite a obtenção de lipossomas em escala piloto de $1 \mathrm{~L}$ de preparação lipossômica, sendo possível sua utilização em escala industrial (Mozafar, 2005). Lipossomas preparados para obter os aniônicos complexados com cálcio e DNA foram obtidos pelo método de aquecimento (Mozafari, 2005).

Um método de produção de lipossomas utilizando um sistema multitubular com a possibilidade de escalonamento industrial foi proposto por Carneiro e Santana (2004). Nesse processo, os fosfolípidios são dissolvidos em etanol e bombeados para diversos módulos de vidro, promovendo a adsorção dos lipídios. O filme lipídico formado é então secado a vácuo $\left(200 \mathrm{mBar}\right.$ a $\left.80^{\circ} \mathrm{C}\right)$ e hidratado com uma solução tampão formando, então, os lipossomas. A eficiência de encapsulação da pirazinamida utilizando o método multitubular foi de $14,7 \%$, quando o fármaco foi colocado na solução de hidratação, ou de $6,7 \%$, quando adicionado à mistura de lipídios inicial, respectivamente. O escalonamento do processo pode ser efetivado pelo aumento do tamanho dos tubos ou no número de tubos no sistema modular.

\section{Estabilidade}

A estabilidade de lipossomas pode ser afetada por processos químicos, físicos e biológicos. Dependendo da sua composição, as formulações finais dos lipossomas podem apresentar um curto tempo de meia-vida, em parte devido à instabilidade física e química (Sharma, Sharma, 1997). A avaliação da estabilidade deve incluir a caracterização do produto final e o acompanhamento da estabilidade durante o armazenamento da formulação lipossômica (Vemuri, Rhodes, 1995).

Instabilidade química - Os processos químicos de instabilidade são dependentes da composição dos lipossomas, a qual implica na prevenção da hidrólise do éster e da oxidação da insaturação localizada na cadeia lipídica. Como apresentado por Saerten et al. (2005), a hidrólise lipídica leva à formação de um produto intermediário, a liso-fosfatidilcolina (liso-PC). A presença da lisoPC acentua a permeabilidade dos lipossomas, o que prejudica a integridade da formulação. Os autores afirmaram ainda que a variação de $\mathrm{pH}$ favorece a hidrólise dos lipídeos e que um pH em torno de 6,0 é mais favorável para manter a estabilidade da formulação.

Esses problemas podem ser superados pela conservação dos lipossomas em atmosfera de nitrogênio e argônio, pelo uso de antioxidantes como alfa-tocoferol na preparação, como também pela liofilização da formulação final com a ajuda de um crioprotetor. A liofilização aumenta a meia-vida da formulação lipossômica, pela maior estabilidade em estado seco, podendo ser reconstituída com veículo na hora da administração (Cacela, Hincha, 2006; Sharma, Sharma, 1997).

Instabilidade física - Alguns dos principais processos que causam a instabilidade dos lipossomas são a agregação e fusão das vesículas e o extravasamento do fármaco encapsulado. A inclusão de uma pequena quantidade de lipídeos com carga (p.ex., estearilamina ou dicetilfosfato) na preparação de lipossomas produz repulsão eletrostática entre as vesículas, reduzindo a agregação e a fusão das vesículas. O acréscimo de colesterol e esfingomielina na formulação pode diminuir a permeabilidade e o extravasamento do fármaco encapsulado e pode ainda aumentar a temperatura de transição de fase (Tc), melhorando desta forma a estabilidade. $\mathrm{O}$ colesterol pode ser adicionado, reduzindo a fluidez e deformação da membrana (Yarosh, 2001). Em altas concentrações (> $30 \mathrm{~mol} \%$ ), o colesterol pode diminuir a fluidez da membrana a temperatura maior que a Tc, com produção de lipossomas mais estáveis e com pouco extravasamento após administração sistêmica (Sharma, Sharma, 1997).

Instabilidade biológica - Um dos maiores pré-requi- 
sitos para o uso de lipossomas como carreadores de fármacos in vivo é que eles devem circular e reter o fármaco por tempo suficiente para o acesso efetivo e interação com o alvo, normalmente no sangue, nas paredes dos capilares e, em certos casos, em células de áreas extravasculares (Freund et al., 2000). A estabilidade biológica depende da presença de agentes que interagem com os lipossomas, estando, portanto, vinculada com a via de administração (Lasic, 1998).

A grande desvantagem dos lipossomas convencionais tem sido sua rápida remoção do sangue, devido à adsorção às proteínas do plasma (opsoninas) pelos fosfolipídeos da membrana, desencadeando o reconhecimento e a captura dos lipossomas pelo sistema fagocitário mononuclear (Sapra, Allen, 2003). Este sistema é composto de células (macrófagos e monócitos) capazes de remover corpos estranhos da circulação sanguínea e de fornecer células fagocitárias em processos inflamatórios seguido de seu recrutamento pelas citocinas ou proteínas do sistema complemento (Vonarbourg et al., 2006).

Vários parâmetros físico-químicos influenciam na eliminação dos lipossomas da circulação, dentre eles o tamanho das vesículas, a natureza dos componentes lipídicos, a carga elétrica da superfície, o reconhecimento pelo sistema complementar e o reconhecimento pelos macrófagos (Vonarbourg et al., 2006).

Laverman et al. (1999) relataram estudo sobre o efeito do tamanho das vesículas sobre a taxa de remoção de lipossomas de composição lipídica idêntica, variando-se o tamanho (200 e $400 \mathrm{~nm}$ ). Uma diferença significativa foi observada, visto que os lipossomas grandes foram removidos do sangue mais rapidamente, com tempo de meia-vida $\left(\mathrm{t}_{1 / 2}\right)=0,2 \mathrm{~h}$, comparado com as vesículas menores que apresentaram $\mathrm{t}_{1 / 2}=1,5 \mathrm{~h}$.

Sengupta et al. (2000) afirmaram que a incorporação de colesterol na formulação de lipossomas carregados positivamente contendo etoposídeo, um agente antineoplásico, aumentou a estabilidade dos lipossomas em soro, constituindo um dos fatores mais importantes na manutenção da integridade da membrana das vesículas e dessa forma prolongando o tempo de circulação in vivo. Lipossomas pobres ou livres de colesterol são predominantemente localizados no fígado após sua administração. Já as vesículas constituídas com grande proporção de colesterol tendem a se concentrar mais efetivamente no baço e medula óssea (Moghimi, 1998).

A carga da superfície dos lipossomas pode ser manipulada pela introdução de lipídeos neutros, como também carregados positivamente ou negativamente na bicamada lipídica. Em geral, a presença de uma carga eletrostática na superfície dos lipossomas promove a interação com biomoléculas, tais como as opsoninas, e com células, sendo então removidos mais rapidamente da circulação do que os lipossomas neutros (Laverman et al., 1999). Banerjee (2001) afirma que a captura de lipossomas carregados negativamente no baço é aproximadamente duas vezes maior do que os carregados positivamente.

A hidrofilia conferida à superfície dos lipossomas furtivos $\left(\right.$ Stealth $\left.{ }^{\circledR}\right)$ estende a meia-vida em meio biológico de poucos minutos (lipossomas convencionais) para várias horas, visto que a incorporação de componentes hidrofílicos torna os lipossomas furtivos, evitando o reconhecimento e captura destes pelo sistema fagocitário mononuclear. De acordo com Sihorkar e Vyas (2001), a incorporação de biomoléculas (ligantes) de reconhecimento em carreadores coloidais como os lipossomas confere estabilidade e melhora à integridade de sua estrutura, depois de serem administrados por via oral ou parenteral. De fato, Sadzuka et al. (2006) relataram que lipossomas com superfície modificada com polietileneglicol (PEG) contendo doxorrubicina, agente antineoplásico, apresentaram capacidade furtiva (longa circulação) e com acumulação do fármaco na área tumoral.

\section{Aplicações terapêuticas}

\section{Lipossomas no tratamento do câncer}

Embora a indústria farmacêutica seja bem sucedida no descobrimento de novos fármacos citotóxicos que são candidatos em potencial para o tratamento do câncer, esta doença causa mais de seis milhões de mortes por ano em todo o mundo e este número continua crescente (Andresen et al., 2005). A terapia com fármacos antineoplásicos causa toxicidade sistêmica, resultando em citotoxidade para as células normais. Parte das células cancerígenas tem características muito comuns com as células normais, das quais foram originadas. Deste modo, torna-se difícil encontrar um alvo único contra o qual os fármacos possam ser direcionados. Os efeitos colaterais associados à quimioterapia limitam a dose ou doses cumulativas administradas aos pacientes que podem, entretanto, levar a metástases do tumor e, muitas vezes, o desenvolvimento de resistência contra os fármacos (Sapra, Allen, 2003).

Uma estratégia alternativa para estes inconvenientes é o uso de lipossomas como carreadores de fármacos antineoplásicos, para alcançar a acumulação seletiva do fármaco no tecido, onde se encontra o tumor ou nas células tumorais. Carreadores lipossômicos têm sido aceitos clinicamente no tratamento do câncer, visto que eles alteram a farmacocinética e biodistribuição dos fármacos antineoplásicos (Mamot et al., 2003).

Andrade et al. (2004) constataram que a encapsulação da lectina de Cratylia mollis (Cra) em lipossomas produziu um aumento da atividade antitumoral in vivo 
contra Sarcoma 180 comparando-se com o tratamento com Cra em solução. Além disso, a análise histopatológica revelou que a encapsulação da Cra produziu uma redução no efeito hepatóxico.

Tem sido demonstrado que os lipossomas de longa duração podem ser passivamente direcionados para vários tipos de tumores, pelo fato de eles poderem circular por tempo prolongado e extravasar nos tecidos com permeabilidade vascular elevada. Tumores sólidos crescentes, assim como regiões de infecção e inflamação, têm capilares com permeabilidade aumentada como resultado da angiogênese. $\mathrm{O}$ diâmetro dos poros desses capilares pode se estender de 100 a $800 \mathrm{~nm}$. Os lipossomas contendo o fármaco têm diâmetros que se estendem de aproximadamente 60 a $150 \mathrm{~nm}$. Portanto, são pequenos o suficiente para extravasar do sangue para o espaço intersticial do tumor passando através desses poros (Lasic, 1998; Sapra, Allen, 2003).

Chou et al. (2006) avaliaram a atividade da doxorrubicina encapsulada em lipossomas furtivos (LipoDox $^{\circledR}$ ) em pacientes com carcinoma ovariano epitelial resistente à platina na dose de $45 \mathrm{mg} / \mathrm{m}^{2}$ a cada quatro semanas. A eficácia do Lipo-Dox foi constatada em câncer recorrente e platina-resistente. Um perfil de baixa toxicidade foi verificado com avaliação de parâmetros fisiológicos, bioquímicos e de imagem.

O direcionamento ativo é a estratégia de acoplar um ligante específico na superfície dos lipossomas, aumentando sua seletividade de interação com as células ou tecido tumoral, através da ligação destes com marcadores específicos localizados na membrana da célula ou do tecido. Lukyanov et al. (2004) modificaram lipossomas de longa duração contendo doxorrubicina, comercialmente disponíveis como Doxil ${ }^{\circledR}$, com anticorpos monoclonais que reconhecem antígenos da superfície do tumor, mas não de células normais. Um aumento da citotoxidade desses lipossomas sítio-específicos foi constatado nas células cancerígenas.

Na terapia fotodinâmica, por exemplo, modalidade para tratamento de tumores superficiais envolvendo a administração sistêmica de fotossensores, o direcionamento ativo destes por lipossomas (com PEG ou anticorpos acoplados na superfície) aumenta a acumulação seletiva do fármaco no tumor. Os lipossomas potencializam o efeito fotodinâmico devido à internalização celular do fotossensor, minimizando os efeitos colaterais observados na terapia fotodinâmica convencional (Derycke, Witte, 2004).

\section{Lipossomas no desenvolvimento de vacinas}

A proteção limitada fornecida pela maioria das estratégias de vacinação direcionou as pesquisas para a investigação de vacinas alternativas, focadas no desenvolvimento de adjuvantes efetivos e sistemas de liberação controlada. Os lipossomas têm sido propostos como veículos de liberação de antígenos em razão de sua utilidade como adjuvante imunológico, apresentando vantagens como sua fácil preparação, baixa toxicidade, biocompatibilidade e biodegradabilidade, assim como a liberação lenta de antígenos encapsulados (Ben-Yehuda et al., 2003; Mazumdar et al., 2004).

Antígenos peptídicos ou protéicos são fagocitados por macrófagos e eventualmente acumulados em lisossomas. Nos lisossomas, os peptídeos degradados são apresentados ao complexo de histocompatibilidade classe II, ligado na superfície dos macrófagos, resultando na estimulação das células T-helper específicas e, finalmente, na estimulação de células B específicas, o que resulta na subseqüente secreção de anticorpos (Torchilin, 2005).

Uma estratégia para aumentar o efeito da vacina é liberar especificamente o antígeno no órgão alvo. A conjugação de proteínas virais na membrana de lipossomas (virossomas) oferece a oportunidade para explorar o direcionamento e propriedades fusogênicas de membranas de proteínas virais. Esta propriedade dribla o inconveniente da degradação pelos lisossomas antes de alcançarem o citoplasma, pois os virossomas são usados como o próprio vírus, introduzindo o material dentro do citoplasma (Kaneda, 2000; Singh, O’Hagan, 2003).

Outra vantagem dos virossomas é o ganho do tropismo do tecido pela proteína viral. Alguns vírus são direcionados para células ou tecidos específicos: Epstein-Barr vírus (EBV) o qual infecta principalmente linfócitos $\mathrm{B}$, vírus da hepatite B, que ataca os hepatócitos, e HIV direcionados para os linfócitos e macrófagos (Kaneda, 2000).

Minato et al. (2003) realizaram um estudo avaliando o efeito do uso de lipossomas PEG-modificados na administração oral de vacina utilizando ovalbumina como modelo de antígeno. Concluíram que lipossomas peguilados melhoram a imunidade da mucosa, provavelmente devido à liberação controlada de antígenos dos lipossomas para a mucosa local. Por outro lado, os lipossomas estimularam o sistema imune, possivelmente, devido ao aumento do tempo de permanência dos lipossomas PEG-modificados na circulação.

Mazumdar et al. (2004) desenvolveram uma vacina lipossômica contendo antígenos na membrana de promastigota de Leishmania donovani. O estudo concluiu que a imunização com este antígeno em lipossomas induziu a produção de anticorpos específicos, como também a resistência contra uma infecção progressiva causada pela Leishmania donovani.

\section{Lipossomas na terapia gênica}

Desde os primeiros testes da terapia gênica em humanos, em 1989, centenas de protocolos clínicos envolvendo 
transferência gênica têm sido iniciadas em todo o mundo. Atualmente, a terapia gênica é estudada para uma grande quantidade de doenças congênitas incluindo doença vascular periférica, artrite, desordens neurodegenerativas, síndrome da imunodeficiência adquirida (AIDS) e, principalmente, o câncer (Mhashilkara et al., 2001; Zhao, Lee, 2004). Para se conseguir a transferência do material genético para o interior das células alvo utilizam-se veículos, que na terapia gênica podem ser divididos em dois grupos: os sistemas biológicos e os não-biológicos. Cada grupo tem suas vantagens e limitações. Estas limitações são menos encontradas em carreadores de genes não-virais, como por exemplo, os lipossomas (El-Aneed, 2004). Os lipossomas catiônicos interagem com o DNA através de interações eletrostáticas, já que a molécula de DNA é carregada negativamente. A carga total, no entanto, mantém-se com valor positivo. Isto vai permitir a interação eficiente do carreador com a carga negativa da membrana celular, penetrando na célula, principalmente através de endocitose.

A viabilidade de encapsular passivamente DNA em lipossomas foi demonstrada na década de 1970. No entanto, foi nos anos 1980 a descoberta de que lipídeos catiônicos, quando incorporados em lipossomas, poderiam aumentar a eficiência de transfecção gênica em células cultivadas in vitro, resultante do aumento da associação dos complexos DNA-plasmídeo com lipossomas catiônicos e da interação destes com células. Desde então, muitas pesquisas estão sendo realizadas no intuito de sintetizar lipídeos catiônicos que mostrem melhora na transferência gênica e tolerabilidade das propriedades celulares, assim como o desenvolvimento de novas propriedades de encapsular eficientemente o DNA em lipossomas (Chonn, Cullis, 1998). Estudos imunológicos recentes têm demonstrado que a transfecção gênica e a subseqüente ativação de células dendrídicas (CDs) são os principais eventos no desenvolvimento da imunidade seguida da vacinação com DNA. O aumento da resposta imune através da vacinação com DNA, utilizando lipossomas catiônicos com manosil na superfície foi a proposta do estudo de Hattori et al. (2004). A avaliação do aumento da resposta imune foi obtida através da expressão do gene da ovoalbumina e a apresentação de antígenos nas células dendrídicas CD11 $\mathrm{c}^{+}$ no baço, depois da administração intravenosa de lipossomas catiônicos contendo ovoalbumina. Os resultados apresentaram aumento tanto na expressão gênica como na secreção de antígenos, sugerindo que a liberação direcionada de vacinas com DNA pelos lipossomas constitui um importante método para imunização eficaz.

\section{Lipossomas na terapia de doenças infecciosas e parasitárias}

A tendência dos lipossomas de serem capturados pelo sistema fagocitário mononuclear (SFM) pode ser uma vantagem no tratamento de variedade de doenças infecciosas intracelulares. Labana et al. (2002) avaliaram a eficácia de lipossomas contendo isoniazida e rifampicina contra a tuberculose com doses de 12 e $10 \mathrm{mg} / \mathrm{kg}$, respectivamente, administrados uma vez por semana em camundongos infectados com Mycobacterium tuberculosis. Os resultados mostraram que a formulação exibiu liberação controlada dos fármacos no plasma durante 5 dias, sendo verificada a presença de fármacos no pulmão, fígado e baço 7 dias após administração. Os resultados mostraram ainda que a formulação diminuiu significativamente a carga micobacteriana no pulmão, fígado e baço de ratos infectados, comparados com os animais não tratados.

O aumento de 200 a 700 vezes na eficácia de antimoniais pentavalentes encapsulados em lipossomas foi observado no tratamento da leishmaniose visceral em hamsters ou camundongos infectados por Leishmania donovani. Este fato pode ser atribuído à captura dos lipossomas pelos órgãos (fígado, baço e medula óssea) e células (os macrófagos teciduais) nas quais se localizam os parasitas causadores da doença (Frézard et al., 2005).

Lipossomas de tamanho reduzido contendo antimoniato de meglumina apresentaram aumento no direcionamento para a medula óssea de cachorros com leishmaniose visceral e alta retenção de antimônio nesse tecido, quando comparado com o tratamento com o fármaco livre e a com relação à formulação lipossômica com tamanho de vesículas maiores (Schettini et al, 2006).

Badiee e colaboradores (2007) encapsularam a proteína 1 (rLmSTH) de Leishmania major em lipossomas e verificaram a redução no número de parasitas vivos e o aumento na produção de $\mathrm{IgG} 2 \mathrm{a}$ em camundongos $\mathrm{Balb} / \mathrm{c}$ imunizados com a vacina lipossômica. A resposta imune foi considerada do tipo Th1.

Melo et al. (2003) comprovaram a habilidade dos lipossomas em aumentar a eficácia do tartarato de antimônio e potássio (tártaro emético) contra infecção com Schistosoma mansoni. Lipossomas convencionais e de longa circulação foram empregados no tratamento dos animais infectados, sendo que o grupo tratado com lipossomas furtivos $(27 \mathrm{mg} / \mathrm{kg})$ apresentou redução significativa no número de vermes ( $82 \%$ ) comparado com o grupo controle. A formulação lipossômica promoveu redução na toxicidade do tartarato de antimônio e potássio.

Mourão et al. (2005) avaliaram a eficiência do praziquantel (PZQ), fármaco de primeira escolha no tratamento da esquistossomose, encapsulado em lipossomas no tratamento de camundongos BalbC infectados com $S$. mansoni. Os resultados mostraram que os lipossomas contendo PZQ foram mais eficazes na redução de vermes comparada com o fármaco livre. 
Lipossomas aplicados em outras terapias

A liberação local de fármacos em doenças cardiovasculares consiste em grande potencial terapêutico. Lestini et al. (2002) modificaram a superfície de lipossomas com peptídeo de ácido aspártico-arginina-glicina para direcionamento para as integrinas GPIIb-IIIa de plaquetas ativadas envolvidas na doença cardivascular restenose. Os resultados indicaram que os peptídeos foram capazes de direcionar os lipossomas para os receptores expressados nas plaquetas ativadas evitando a agregação plaquetária.

Zhang et al. (2005) investigaram a atividade da insulina encapsulada em lipossomas modificados com lectina conjugada na superfície e constataram um efeito hipoglicemiante em camundongos diabéticos após administração oral dos lipossomas contendo insulina (350 IU/kg). Redução de 33,4\% nos níveis de glicose sanguínea foi observada para lipossomas lectinizados.

\section{CONCLUSÃO}

A multidisciplinaridade associada à nanotecnologia farmacêutica (física, química, biologia e farmacologia) resultou no desenvolvimento de lipossomas como sistemas de liberação de fármacos eficazes na terapêutica do câncer e de infecções. Autilidade dos lipossomas foi melhorada seguindo pesquisas básicas que permitiram o aumento da estabilidade e a compreensão das características físicoquímicas e interação com fluidos biológicos.

Devido à sua versatilidade estrutural em termos de tamanho, composição, carga da superfície, fluidez da membrana e habilidade para incorporar fármacos hidrofílicos e/ ou lipofílicos, lipossomas se tornaram potentes carreadores para vários tipos de terapias, aumentando a eficácia e reduzindo os efeitos tóxicos dos fármacos. Inúmeros trabalhos de desenvolvimento de formulações com objetivo terapêutico para várias doenças relatam a eficácia e a segurança dos tratamentos realizados com formulações lipossômicas, constatando uma grande vantagem em relação aos tratamentos convencionais. Já são comercializadas formulações contendo lipossomas para o tratamento do câncer e infecções sistêmicas por fungos. O aprofundamento das pesquisas irá possibilitar a consolidação de seu uso na terapia gênica e em vacinas.

\section{ABSTRACT}

\section{Liposomes and their therapeutic: state of art applications}

Liposomes are vesicles that consist of one or more concentric phospholipidic bilayers organized around an aqueous inner compartment. They are carriers of drugs, biomolecules and diagnostic agents. The stability of liposomes can be influenced by chemical or physical factors. Once injected in the circulatory system, conventional liposomes suffer uptake by the mononuclear phagocytic system. To avoid such a capture, nonconventional or Stealth ${ }^{\circledR}$ liposomes were developed, which are coated by hydrophilic components. Specific ligand had been incorporated in their surface so as to control the drug release and selectivity, thereby originating the targeted liposomes. In general, all preparation methods of liposomes include the hydration of lipidic film followed by sonication or extrusion to reduce the mean size of vesicles. After preparation, the vesicles are characterized by size, chemical constitution, and amount of encapsulated material. In this review it is shown that the liposomes offer effectiveness and safety in comparison with many conventional treatments. In spite of the existence of a few liposomal formulations available since early 80 's, which are used for the treatment of systemic fungal infections and cancer, many technological and biological issues remain as a challenge. In this scenario, liposomes have extensively been studied in order to improve their in vivo stability in the treatment of several diseases, including cancer.

UNITERMS: Liposomes. Phospholipids. Stability. Therapeutic applications.

\section{REFERÊNCIAS BIBLIOGRÁFICAS}

AMSELEM, S., GABIZON, A., BARENHOLZ, Y. A large scale method for the preparation of sterile and nonpyrogenic liposomal formulations of defined size distributions for clinical use. In: GREGORIADIS, G. (Ed.). 2. ed. Liposome technology. Boca Raton: CRC Press, 1993. v. 1, p. 459, p. 501-525.

ANABOUSI, S., BAKOWSKY, U., SCHNEIDER, M., HUWER, H., LEHR, C.-M., CHRARDT, C. In vitro assessement of transferrin-conjugated liposomes as drug delivery systems for inhalation therapy of lung cancer. Eur. J. Pharm. Sci., v. 29, p.367-374, 2006.

ANDRADE, C.A. S.; CORREIA, M. T. S.; COELHO, L. C. B. B.; NASCIMENTO, S. C.; SANTOSMAGALHÃES, N. S. Antitumor activity of Cratylia mollis lectin encapsulated into liposomes. Int. J. Pharm., Amsterdam, v. 278, p.435-445, 2004. 
ANDRESEN, T. L.; JENSEN, S. S.; JORGENSEN, K. Advanced strategies in liposomal cancer therapy: Problems and prospects of active and tumor specific drug release. Prog. Lipid Res., Oxford, v. 44, p.68-97, 2005.

BADIEE, A.; JAAFARI, M.R.; KHAMESIPOUR, A. Leishmania major: Immune response in $\mathrm{BALB} / \mathrm{c}$ mice immunized with stree-inducible protein 1 encapsulated in liposomes. Exp. Parasitol., v. 115, p. 127-134, 2007.

BANERJEE, R. Liposomes: aplications in medicine. $J$. Biomat. Applied, London, v. 16, p. 3-21, 2001.

BEN-YEHUDA, A.; JOSEPH, A.; BARENHOLZ, Y.; ZEIRA, E.; EVEN-CHEN, S.; LOURIA-HAYON, I.; BABAI, I.; ZAKAY-RONES, Z.; GREENBAUM, E.; GALPRIN, I.; GLÜCK, R.; ZURBRIGGEN, R.; KEDAR, E. Immunogenicity and safety of a novel IL-2supplemented liposomal influenza vaccine (INFLUSOME-VAC) in nursing-home residents. Vaccine, Kidlinton, v. 21, p. 3169-3178, 2003.

CACELA, C.; HINCHA, D. K. Low amounts of sucrose are sufficient to depress the phase transition temperature of dry phosphatidylcholine, but not for lyoprotection of liposomes. Biophys. J., Bethesda, v. 90, p.2831-2842, 2006.

CARNEIRO, A.L.; SANTANA, M. H. A. Production of liposomes in a multitubular system useful for scaling-up of processes. In: GALEMBEK, F. (Ed.). Progress in Colloid \& Polymer Science, Surface and Colloid Science. New York: Springer, 2004. v. 128, p. 273-276.

CARVALHO Jr, A. D.; MOTA, L.G.; NUNAN, E. A.; WAINSTEIN, A. J. A.; WAINSTEIN, A.P.D.L.; LEAL, A. S.; CARDOSO, V. N.; OLIVEIRA, M. C. Tissue distribution evaluation of stealth $\mathrm{pH}$-sensitive liposomal cisplatin versus free cisplatin in Ehrlich tumor bearing mice. Life Sci., v. 80, p. 659-664, 2007.

CHONN, A.; CULLIS, P. R. Recent advances in liposomes technologies and their applications for systemic gene delivery. Adv. Drug Del. Rev., Amsterdam, v. 30, p. 73-83, 1998.
CHOU, H.; WANG, K.; CHEN, C.; WEI, L.; LAI, C.; HSIEH, C.; YANG, Y.; TWU, N.; CHANG, T.; YEN, M. Pegylated liposomal doxorubicin (Lipo-Dox ${ }^{\circledR}$ ) for platinum-resistant or refractory epithelial ovarian carcinoma: A Taiwanese gynecologic oncology group study with long-term follow-up. Gynecol. Oncol., New York, v. 101, p.423-428, 2006.

DASS, C. R.; CHOONG, P. F. M. Carrier-mediated delivery of peptidic drugs for cancer therapy. Peptides, New York, v. 27, p. 3020-3028, 2006.

DERYCKE, A. S. L.; WITTE, P. A. M. Liposome for photodynamic therapy. Adv. Drug Del. Rev., Amsterdam, v. 56, p. 17-30, 2004.

EDWARDS, K. A.; BAEUMNER, A. J. Liposomes in analyses. Talanta, London, v. 68, n.5, p.1432-1441, 2006.

EL-ANEED, A. An overview of current delivery systems in cancer gene therapy. J. Controlled Release, Amsterdam, v. 94, p. 1-14, 2004

FREUND, O.; AMÉDEE, J.; ROUX, D.; LAVERSANNE, R. In vitro and in vivo stability of new multilamellar vesicles. Life Sci., Elmsford, v. 67, p. 411-419, 2000.

FRÉZARD, F. Liposomes: from biophysics to the design of peptide vaccines. Braz. J. Med. Biol. Res., Ribeirão Preto, v. 32, p. 181-189, 1999.

FRÉZARD, F.; SCHETTINI, D. A.; ROCHA, O. G. F.; DEMICHELI, C. Lipossomas: propriedades físicoquímicas e farmacológicas, aplicações na quimioterapia à base de antimônio. Quim. Nova, São Paulo, v. 28, p.511$518,2005$.

HATTORI, Y.; KAWAKAMI, S.; SUZUKI, S.; YAMASHITA F.; HASHIDA, M. Enhancement of immune responses by DNA vaccination through targeted gene delivery using mannosylated cationic liposome formulations following intravenous administration in mice. Biochem. Biophys. Res. Comm., Orlando, v. 317, p. 992-999, 2004.

KANEDA, Y. Virosomes: evolution of the liposome as a targeted drug delivery system. Adv. Drug Del. Rev., Amsterdam, v. 43, p. 197-205, 2000. 
KERSTEN, G. F. A.; CROMMELIN, D. J. A. Liposomes and ISCOMs. Vaccine, Kidlinton, v. 21, p. 915-920, 2003.

KIKUCHI, H., CARLSSON, A., YACHI, K., HIROTA, S. Possibility of heat sterilization of liposomes. Chem. Pharm. Bull., v. 39, p. 1018-1022, 1991.

LABANA, S.; PANDEY, R.; SHARMA, S.; KHULLER, G.K. Chemotherapeutic activity against murine tuberculosis of once weekly administered drugs (isoniazid and rifampicin) encapsulated in liposomes. Int. J. Antimicrob. Agents, London, v. 20, p.301-304, 2002.

LASIC, D. D. Liposomes: from physics to applications. $1^{\mathrm{a}} \mathrm{ed}$. Amsterdam: Elsevier Science Publishers B. V., cap.3, p.63-90, 1993.

LASIC, D. D. Novel applications of liposomes. Tibtech., v. 16, p. 307-320, 1998.

LAVERMAN, P.; BOERMAN, O. C.; OYEN, W. J. G.; DAMS, E. Th. M.; STORM, G.; CORSTENS, F. H. M. Liposomes for scintigraphic detection of infection and inflammation. Adv. Drug Del. Rev., Amsterdam, v. 37, p. 225-235, 1999.

LESTINI, B. J.; SAGNELLA, S. M. , XU, Z; SHIVE, M. S.; RICHTER, N. J.; JAYASEHARAN, J.; CASE, A. J.; KOTTKE-MARCHANT, K.; ANDERSON, J. M.; MARCHANT R. E. Surface modification of liposomes for selective cell targeting in cardiovascular drug delivery. J. Controlled Release, Amsterdam, v. 78, p. 235-247, 2002.

LU, Y., KAWAKAMI, S., YAMASHITA, F., HASHIDA, M. Development of an antigen-presenting cell-targeted DNA vaccine against melanoma by mannosylated liposomes. Biomaterials, Surrey, v. 28, p. 3255-3262, 2007.

LUKYANOV, A. N.; ELBAYOUMI, T. A.; CHAKILAM,A. R.; TORCHILIN, V.P. Tumor-targeted liposomes: doxorubicin-loaded long-circulating liposomes modified with anti-cancer antibody. J. Controlled Release, Amsterdam, v. 100, p.135-144, 2004.

MAMOT, C.; DRUMMOND, D. C.; HONG, K.; KIRPOTIN, D.B.; PARK, J. W. Liposome-based approaches to overcome anticancer drug resistance. Drug Res. Update, Amsterdam,v. 6, p. 271-279, 2003.
MASSING, U.; FUXLUS, S. Liposomal formulations of anticancer drugs: selectivity and effectiveness. Drug Res. Update, Amsterdam, v. 3, p. 171-177, 2000.

MAZUMDAR, T.; ANAM, K.; ALI, N. A mixed Th1/Th2 response elicited by a liposomal formulation of leishmania vaccine instructs $T h 1$ responses and resistance to Leishmania donovani in susceptible BALB/c mice. Vaccine, Kidlinton, v. 22, p. 1162-1171, 2004.

MELO A. L.; SILVA-BARCELLOS N. M.; DEMICHELI C.; FRÉZARD, F. Enhanced schistosomicidal efficacy of tartar emetic encapsulated in pegylated liposomes. Int. J. Pharm., Amsterdam, v. 255, p.227-230, 2003.

MHASHILKARA,A.; CHADA, S.; ROTH, J.; RAMESHB, R. Gene therapy therapeutic approaches and implications. Biotechnol. Adv., New York, v. 19, p. 279-297, 2001.

MINATO, S.; IWANAGA, K.; KAKEMI, M.;YAMASHITA,S.; OKU, N. Application of polyethyleneglycol (PEG)-modified liposomes for oral vaccines: effect of lipid dose on systemic and mucosal immunity. J. Controlled Release, Amsterdam, v. 89, p. 189-197, 2003.

MOGHIMI, S. M. Opsono-recognition of liposomes by tissue macrophages. Int. J. Pharm., Amsterdam, v. 162, p.11-18, 1998.

MORTAZAVI, S.M, MOHAMMADABADI, M.R., KHOSRAVI-DARANI, K., MOZAFARI, M.R. Preparation of liposmal gene therapy vectors by a scalable method without using volatile solvents or detergents. $J$. Biotechnol., Amsterdam, v. 129, p. 604-613, 2007.

MOURÃO, S. C.; COSTA, P. I.; SALGADO, H. R. N.; GREMIÃO, M. P. D. Improved of antischistosomal activity of praziquantel by incorporation into phosphatidylcholine-containing liposomes. Int. J. Pharm., Amsterdam, v. 295, p. 157-162, 2005.

MOZAFARI, M.R. Liposomes: an overview of manufacturing techniques. Cell. Mol. Biol. Lett., Washington, v. 10, p. 711-719, 2005.

NEEDHAM, D.; McINTOSH, T. J.; LASIC, D. D. Repulsive interactions and mechanical stability of polymer-grafted lipid membranes. Biochim. Biophys. Acta, Amsterdam, v. 1108, p. 40-48, 1992. 
NEW, R.R.C. (Ed.). Liposomes: A practical approach, IRL/ Oxford University Press, Oxford, 1990. p.432.

PUisiEUX, F. COUVREUR, P., DELATTRE, J., DEVISAGUET, J.P. (Eds.). Liposomes, new systems and new trends in their applications. Paris: Éditions de Santé, 1995. p.266.

SADZUKA, Y.; SUGIYAMA, I.; TSURUDA, T.; SONOBE, T. Characterization of cytotoxicity of mixed polyethyleneglycol modified liposomes containing doxorubicin. Int. J. Pharm., Amsterdam, v.312, p.83-89, 2006.

SAETERN, ANN MARI; SKAR, MERETE; BRAATEN, ASMUND; BRANDL, MARTIN. Camptothecincatalyzed phospholipid hydrolysis in liposomes. Int. J. Pharm., Amsterdam, v. 288, p.73-80, 2005.

SAGRISTÁ, M. L.; MORA, M.; MADARIAGA, M. A. Surface modified liposomes by coating with charged hydrophilic molecules. Cell. Mol. Biol. Lett., Washington, v. 5, p. 19-33, 2000.

SANDIP, B. T.; UDUPA, N.; RAO, B. S. S.; DEVI, P. U. Thermosensitive liposomes and localised hyperthermia - an effective bimodality approach for tumour management. Ind. J. Pharmacol., Pondicherry, v. 32, p. 214-220, 2000.

SANTANA, M. H. A., OLIVEIRA, M.C., GREMIÃO, P.D. Lipossomas. In: DURAN, N., MATTOSO, L.H.C., DE MORAIS, P.C. (Eds). Nanotecnologia, introdução, preparação e caracterização de nanomateriais e exemplos de aplicação. Artliber, São Paulo, v. 1, p. 167$173,2006$.

SAPRA, P.; ALLEN, T. M. Ligand-targeted liposomal anticancer drugs. Prog. Lipid Res., Oxford, v. 42, p. 439462, 2003.

SCHETTINI, D. A.; RIBEIRO, R. R.; DEMICHELI, C.; ROCHA, O. G. F.; MELO, M. N.; MICHALICK, M. S. M.; FRÉZARD, F. Improved targeting of antimony to the bone marrow of dogs using liposomes of reduced size. Int. J. Pharm., Amsterdam, v. 315, n. 1-2, p.140147, 2006.
SCHNEIDER, T., SACHSE, A., RObLING, G., BRANDL, M. Large scale production of liposomesof defined size bya new continuous high pressure extrusion device. Drug Dev. Ind. Pharm., Bethesda, v. 20, p. 2787-2807, 1994.

SENGUPTA, S.; TYAGI, P.; VELPANDIAN, T.; GUPTA, Y. K.; GUPTA, S. K. Etoposide encapsulated in positively charged liposomes: pharmacokinetic studies in mice and formulation stability studies. Pharmacol. Res., London, v. 42, n. 5 , p. $459-464,2000$.

SERIKAWA, T., KIKUCHI, A., SUGAYA, S., SUZUKI, N., KIKUCHI, H., TANAKA, K. In vitro e in vivo evaluation of novel cationic liposomes utilized for cancer gene therapy. J. Controlled Release, Amsterdam, v. 113, p. 255-260, 2006.

SHARMA, A.; SHARMA, U. S. Liposome in drug delivery: progress and limitations. Int. J. Pharm., Amsterdam, v. 154, p.123-140, 1997.

SIHORKAR, V.; VYAS, S. P. Potential of polysaccharide anchored liposomes in drug delivery, targeting and immunization. J. Pharm. Sci., Hoboken, v. 4, n. 2, p. 138$158,2001$.

SINGH, M.; O'HAGAN, D. T. Recent advances in veterinary vaccine adjuvants. Int. J. Parasitol., Oxford, v. 33, p. 469478, 2003.

SUZUKI, S., KAWAKAMI, S., CHANSRI, N., YAMASHITA, F., HASHIDA, M. Inhibition of pulmonary metastasis in mice by all-trans retinoic acid incorporated in cationic liposomes. J. Controlled Release, Amsterdam, v. 116, p. 58-63, 2006.

TORCHILIN, V.P. Drug targeting. Eur. J. Pharm. Sci., Amsterdam, p.s81-s91, 2000.

TORCHILIN, V.P. Recent advances with liposomes as pharmaceutical carrier. Nature Rev. Drug Disc., London, v. 4, p. 145-160, 2005.

VEMURI, S.; RHODES, C. T. Preparation and characterization of liposomes as therapeutic delivery systems: a review. Pharm. Acta Helvetica, Berne, v. 70, p.95-111, 1995. 
VONARBOURG, A.; PASSIRANI, C.; SAULNIER, P.; BENOIT, J. Parameters influencing the stealthiness of colloidal drug delivery systems. Biomaterials, Surrey, v. 27, p.4356-4373, 2006.

WAGNER, A., VORAUER-UHL, K., KATINGER, H. Liposomes produced in a pilot scale: production, purification and efficiency aspects. Eur. J. Pharm. Biopharm., Amsterdam, v. 54, p. 213-219, 2002.

WU, J., LEE, A., LU, Y., LEE, R.J. Vascular targeting of doxorubicin using cationic liposomes. Int. J. Pharm., Amsterdam, 2007, doi: 10.1016/j.jpharm.2007.01.003.

YAROSH, D. B. Liposomes in investigative dermatology. Photodermatol. Photoimmunol. Photomed., Denmark, v. 17, p. 203-212, 2001.
ZHANG, N.; PING, Q. N.; HUANG, G. H.; XU, W. F. Investigation of lectin-modified insulin liposomes as carriers for oral administration. Int. J. Pharm., Amsterdam, v. 294, p.247-259, 2005.

ZHAO, X. B.; LEE, R. J. Tumor-selective targeted delivery of genes and antisense oligodeoxyribonucleotides via the folate receptor. Adv. Drug Del. Rev., Amsterdam, v. 56, p. 1193-1204, 2004.

Recebido para publicação em 02 de agosto de 2006. Aceito para publicação em 05 de junho de 2007. 